\title{
The Accuracy Of The Annual Financial Report Data: An Empirical Analysis Of GCC Firms
}

Musa Darayseh, American University of Sharjah UAE

Ismail Gence, American University of Sharjah, UAE

Bassam Abu Al-Foul, American University of Sharjah, UAE

Wissam Abdallah, Lebanese American University, Lebanon

\begin{abstract}
Company's might try to enhance the picture of their income numbers (looks better than it should be) in the eyes of the reader of their annual financial reports. These information could be used by investors and accounting researchers who their decisions depend on the information provided in financial reports. When companies engage in income enhancement, investment decisions may be adversely affected. The objective of this paper is to examine income numbers in a sample of the Gulf Cooperation Council (GCC) firms (UAE, Qatar, Oman, Saudi Arabia, Kuwait and, Bahrain) to determine if the frequency of the second digits conforms to the expected distribution. The results indicate that the null hypothesis could be rejected, suggesting the annual financial data may not be as accurate as expected. In other words, income enhancement at the second digit exists. We also discussed accounting standards that have been used by these companies.
\end{abstract}

Keywords: GCC, Enchantment, Income numbers, Financial reports

\section{INTRODUCTION}

$\mathcal{J}$

here has been a considerable concern by investors and financial analysts regarding Income enhancement in the financial reports. Usually, it is assumed that management prefers a smoothed pattern of income (steady flowing of income to pursued investors and readers of their financial annual report that they do not have problems and they are doing will financially). Therefore, most studies have assumed that it is management's objective to achieve this steady flow of income which is called a smoothed income trends. It may also be an incentive for management to reach key standards and fulfill expectations. This study uses a sample of Gulf Cooperation Council (GCC) firms (UAE, Qatar, Oman, Saudi Arabia, Kuwait and, Bahrain) to investigate the alternative type of income enhancement that management may seek to achieve their goals. At an overall level, investors and financial analysts need to be aware of income enhancement as it can adversely affect their decision-making. At a micro level, the accounting standards under which financial statements are prepared are also of interest to the researcher and investor. The authors found that GCC firms used the International Accounting Standards (IASs) in preparing their annual financial reports. In the remainder of this paper, we first present the accounting standards that been used by the GCC, second, we present the research design and results, and finally we present our conclusion.

\section{ACCOUNTING STANDARDS AT THE GCC}

The Gulf Cooperation Council (GCC) countries adapted IAS, but there are number of areas where they differ in accounting practices. The differences are observed in regulatory and supervisory environments, auditing, and more importantly, the accounting policies and practices. These differences are partly due to their diverse social values and regulatory environments. However, some practices they follow do not match with their socio-cultural and religious norms. The growing cooperation among GCC countries has increased the need for the harmonization of accounting standards that sooner or later has to be addressed by the policy makers in these countries. This harmonization would not 
only increase the transparency and efficiency of the countries' financial institutions, but would also expedite the process of globalization. In this respect, the future research will investigate further differences, and policy prescription will be recommended for their removal. It is to be noted that all differences would not necessary be eliminated but the accounting practices and policies that will have likely impact on the cross-border transactions (such as tax for foreign venture and corporate tax) could be considered, in order to harmonize the accounting practices/ standards in GCC countries. The prime objective of any accounting framework is that the objectives, standards and practices should be heavily influenced by the definitive needs of the users (Radebaugh, 1975).

\section{RESEARCH DESIGN AND RESULTS}

To make good decisions, investors need to be able to rely on financial reporting information, and they need to be aware of attempts of income enhancement. Typically, income enhancement is viewed as a tendency to show smoothing of income, but another possibility for income enhancement exists through the use of key numbers or reference points and the use of rounding of estimates. [Carslaw, 1988] In this form of enhancement, management would attempt to present income numbers that are greater than key reference points rather than slightly less, because of the pressure to meet expectations. In addition, the left-hand figure in the income number is emphasized. If there is uncertainty, estimates will tend to be rounded so that the left-hand figure meets or exceeds expectations. For example, 99,750 would be come 100,000 , rather than 99,000. If this type of rounding is occurring, there should be an abnormal distribution of the second digit in the number, with a lower than expected frequency of high numbers (such as 9) and a higher than expected frequency of lower numbers.

In this paper, the frequency of numbers appearing as the second digit in income numbers of annual reports of a sample of GCC firms was examined to determine if there was an abnormal distribution, indicating the use of this form of income enhancement. The following null hypothesis was tested:

H1: The frequency of numbers appearing in the second place of income numbers in annual reports of GCC firms conform to the expected random distribution.

\section{Data and Sample Selection}

The data includes 310 firms for the periods January 2002 to December 2006 which were obtained from the Gulf Financial Markets as annual data. The method involved counting the number of times that each of the individual numbers 1 through 9 occurred as first digits and counting the number of times that each of the individual numbers 0 through 9 occurred as second digits. A firm was not included in the sample if a decimal point or zero occurred before the first number. Firms having losses were also excluded because rounding of income numbers in negative income years may well differ from rounding in positive income years. The test of the distribution of the first digits evaluated the possibility of bias in the size of the income numbers. The analysis of the distribution of the second digits tested the null hypothesis.

\section{Expected Distribution}

The probability of any digit occurring in a particular place in a number would be one-ninth for the first digit and one-tenth for the later digits. However, Benford [1938] developed a proof regarding the empirical distribution of integers that suggests otherwise. Benford showed that the frequency of an integer (a) that is the first digit of a number chosen randomly from a large body of observations or physical data is

$\mathrm{F}_{\mathrm{a}}=\log \frac{\mathrm{a}+1}{\mathrm{a}}$

where $F_{a}$ is the frequency of the digit a in the first place of chosen numbers.

Benford also extended his model to determine the frequency of an integer (b) appearing as the second digit of any randomly chosen number. 
$\mathrm{F}_{\mathrm{b}}=\frac{\mathrm{ab}+1}{\mathrm{ab}} / \log \frac{\mathrm{a}+1}{\mathrm{a}}$

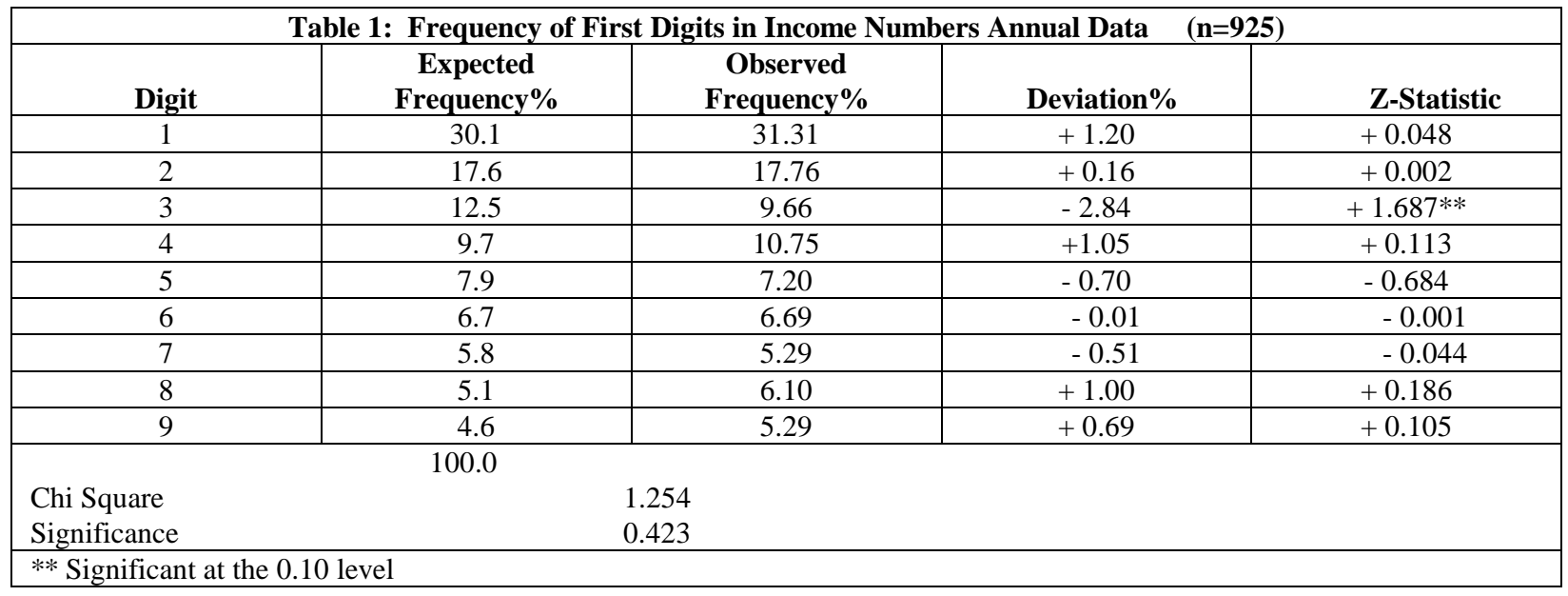

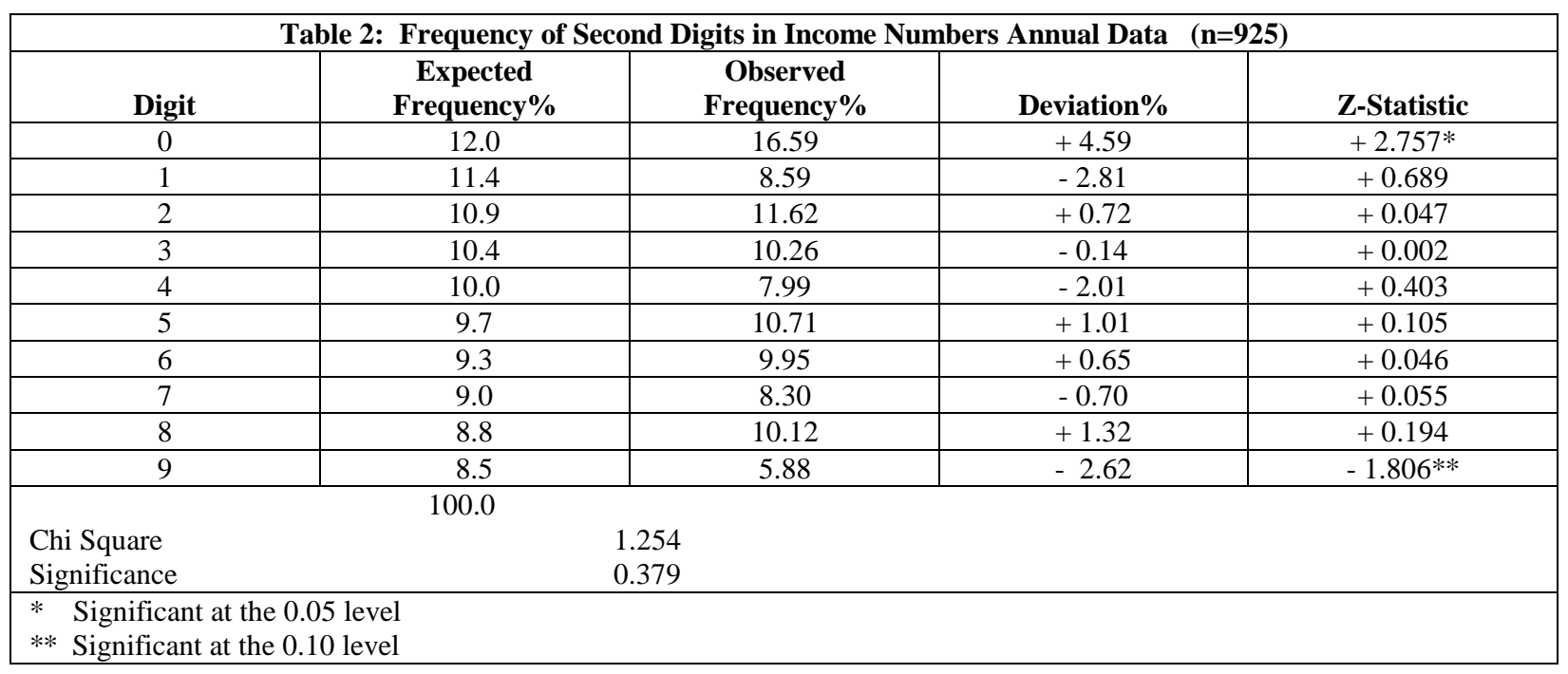

\section{Test on Digits}

Chi-square and the Z-statistic were used to determine the degree of correspondence between the observed and expected observation in each category and to test for bias in the size of the income numbers. The null hypothesis was tested using Chi-square:

$$
\mathrm{X}^{2}=\sum \frac{\left(\mathrm{O}_{\mathrm{i}}-\mathrm{E}_{\mathrm{i}}\right)^{2}}{\mathrm{E}_{\mathrm{i}}}
$$

$\mathrm{O}_{\mathrm{i}}$ is the observed number of cases in each category

$\mathrm{E}_{\mathrm{i}}$ is the expected number of cases in each category

Data from the sample is compared with an assumed population. Expected frequency percentages are derived using Benford's model. A larger $\mathrm{X}^{2}$ value indicates that it is less likely that the observed frequency came from the 
population on which the hypothesis and the expected frequencies are based.

The results for the test for bias in the size of the income numbers are shown in Table 1. There was only one digit with a significant $\mathrm{Z}$ score, indicating that its observed frequency was significantly different than its expected frequency. In general, the distribution of digits (annual reports) conforms to expectation for the first place digits and there appears to be no bias in the size of income numbers for this sample.

The results of the hypothesis test are shown in Table 2. In this table there is evidence of a strong bias toward number having zero as the second digit. The deviation from the expected distribution is significant. Also, there is a less occurrence of number nine as the second digit which is significant at the 10 percent level. This will support to rejection of the hypothesis that the distribution as a whole conform to the expected distributions at the 5 percent and 10 percents. The hypothesis that the frequency of numbers appearing in the second place of income numbers in annual reports do conforms to the expected random distribution can be rejected based on this sample of GCC firms. Chi square is clearly not significant. The observed frequencies of the digits 1 (lower than expected) and 2 (higher than expected) were different than expected, but overall the income figures do not deviate significantly from the expected distribution for the first digits and deviate from expectation for the second digit, suggesting that income enhancement related to key reference points and rounding of estimates is somewhat present.

\section{CONCLUSION}

The objective of this research paper was to look for evidence of the existence of income enhancement which can affect the accuracy of investment decisions. We examined the frequency of occurrence of second digits contained in income numbers of companies listed on the Gulf Financial Markets (annual data) to determine if there was a significantly abnormal distribution, indicating the existence of income enhancement. The results provide evidence that the distribution of the second digits of the income numbers deviates from the expectation. This suggests that an overall level, there has been income enhancement based on rounding of estimates and achieving key reference points.

Interesting comparisons for future research include studying the differences in the quality of financial statement information before and after these countries adoption of IFRS. Also of interest is the continuing debate over the merits of U.S. GAAP versus IFRS. The corporate scandals of recent years have cast a cloud over the efficacy of U.S. GAAP and, with GCC firm's adoption; the influence of IFRS continues to grow. Perhaps in the not too distant future, we will see the convergence of international and U.S. accounting standards. The success of global accounting standards can only improve decision-making by investors worldwide.

\section{AUTHOR INFORMATION}

Musa Darayseh $(\mathrm{PhD})$ is a professor of accounting at the American University of Sharjah. His current research interests include market studies, bankruptcy, and accounting education.

Ismail Gence $(\mathrm{PhD})$ is an associate professor of economics at the American University of Sharjah. His current research interests include monetary theory and policy as well as applied time series econometrics.

Bassam Abu Al-Foul is associate professor of economics at the American University of Sharjah. His current research interests include macroeconomics, natural resources, and international trade.

Wissam Abdallah is assistant professor of finance at the Lebanese American University, Lebanon.

\section{REFERENCES}

1. Ashbaugh, Holly, and Morton Pincus, "Domestic Accounting Standards, International Accounting Standards, and the Predictability of Earnings," Journal of Accounting Research, (39:3), 2001, 417-434.

2. Benford, Frank, "The Law of Anomalous Numbers," Proceedings of the American Philosophical Society, Vol. (78), 1938, 551-572. 
3. Carslaw, A.P.N. Charles, "Anomolies [sic] in Income Numbers: Evidence of Goal Oriented Behavior," The Accounting Review, 1988, 321-327.

4. Colapinto, Robert, "The future direction of accounting standards," CA Magazine, 2005, 20-22.

5. Darayseh, Musa, "Annual and Quarterly Financial Data: Accuracy of Investment Decision,” Journal of Applied Business Research, (8:2), 1992, 20-24.

6. Hope, Ole-Kristian, "Disclosure Practices, Enforcement of Accounting Standards, and Analysts' Forecast Accuracy: An International Study," Journal of Accounting Research, (41:2), 2003, 235-272.

7. IASs and IFRSs, International Accounting Standards and International Financial Reporting Standards, International Accounting Standards Board, www.iasplus.com, 2005.

8. Leuz, Christian, "IAS Versus U.S. GAAP: Information Asymmetry-Based Evidence from Germany's New Market," Journal of Accounting Research, (41:3), 2003, 445-472.

9. Radebaugh, L.H., "Environmental Factors Influencing the Development of Accounting Objectives, Standards and Practice in Peru", The International Journal of Accounting, Vol. 11, (1), 1975, 39-56.

10. Siegel, Sidney, Nonparametric Statistics, 2nd ed. McGraw-Hill, Inc., New York, 1988. 
NOTES 